SAND $77-1433$

Unlimited Distribution

Printed October 1977

\title{
ANALYSIS OF LOW STRESS OIL SHALE HUGONIOTS*
}

\author{
D. E. Munson \\ Geomechanics Research Division 5163 \\ Sandia Laboratories \\ Albuquerque, New Mexico 87115
}

\begin{abstract}
Analysis of low stress Hugoniot data on Anvil Points oil shale was accomplished through careful catagorization of data depending upon density. Density is directly related to kerogen content and kerogen content is a strong variable in determining the Hugoniot. For a given density (kerogen content) the shock velocity-particle velocity data show a minimum in shock velocity believed related to yielding in the rock constituent of the oil shale. Low stress Hugoniot data blena smoothly with tigh pressure data. Further data selection permitted evaluation of the orientation dependence ( 158 in wave speed) of the shock velocity. wave propagation speed in a direction normal to the bedding planes is less than that parallel to the bedding planes. A weak minimum in wave speed occurs between 0 and $45^{\circ}$.
\end{abstract}

This work supported by the U.S. Energy Research and Development Administration, EKDA, under Contract AT(29-1)-789.

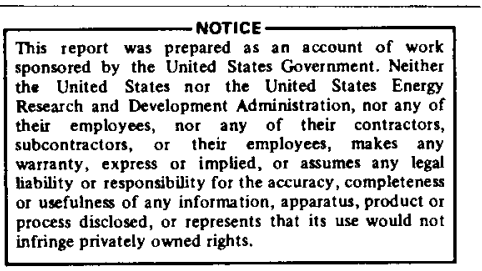


. 


\section{DISCLAIMER}

This report was prepared as an account of work sponsored by an agency of the United States Government. Neither the United States Government nor any agency Thereof, nor any of their employees, makes any warranty, express or implied, or assumes any legal liability or responsibility for the accuracy, completeness, or usefulness of any information, apparatus, product, or process disclosed, or represents that its use would not infringe privately owned rights. Reference herein to any specific commercial product, process, or service by trade name, trademark, manufacturer, or otherwise does not necessarily constitute or imply its endorsement, recommendation, or favoring by the United States Government or any agency thereof. The views and opinions of authors expressed herein do not necessarily state or reflect those of the United States Government or any agency thereof. 


\section{DISCLAIMER}

Portions of this document may be illegible in electronic image products. Images are produced from the best available original document. 


\section{INTRODUCTION}

The author has previously analyzed the available high pressure $(\sigma>5.0 \mathrm{GPa})$ Hugoniot data on Anvil Points oil shale. ${ }^{*}$ Included in this earlier work were a few data points obtained at low stresses, and an extensive collection of ultrasonic data. The principal thrust of the analysis was to quantitatively identify effects of porosity to deduce a kerogen free, solid density shale Hugoniot, and to use simple mixture theory to deduce in a consistent manner an effective kerogen Hugoniot. While the high pressure data suggested little, if any, effect of anisotropy on wave propagation, the limited low stress data on porous material showed a trend suggesting a clear dependence of wave speed on orientation.

Recently, considerably more low stress level data have become available from several sources. These data include a range of kerogen contents and specimen orientations with respect to the direction of wave propagation. All data are from Anvil Points material and hence potentially relatable to one another.

In this paper, we analyze these data, ensemble, paying particular attention to material densities (kerogen content), particle velocity, and orientation. This analysis shows, again, the importance of density variations (kerogen content), and gives an adequate picture of the influence of orientation on the wave speeds. Correlating these results, where possible, with the high pressure data shows a consistent pattern of overall behavior.

\footnotetext{
*Anvil Points oil shale is a mixture of kerogen in a fine-grained marlstone and was obtained from the Anvil Points Mine, Rifle, Co.
} 


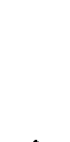




\section{HUGONIOT RESULTS}

The Hugoniot results of interest are those obtained on the material from Anvil Points Mine. Oil shale is a sedimentary rock with readily visible bedding markings. It is a marlestone composed primarily of dolomite, quartz and analcime with various amounts of calcite and albite, and of kerogen, a polymer-like hydrocarbon. While the studies were all performed on material from the same mine, the individual samples were acquired at different times and hence from different mine locations.

It is possible to obtain a range of kerogen contents, ranging from very low, $3 \mathrm{~g} /$ ton $(12 \mathrm{ml} / \mathrm{kg})$, to very high, $80 \mathrm{~g} / \mathrm{ton}(320 \mathrm{ml} / \mathrm{kg})$, in this material; consequently, this is a major variable. A predominant influence of the kerogen content is that it causes a major change in the specimen density which modifies significantly the Hugoniot response. Density variation ranges from 1.4 to $2.4 \mathrm{Mg} / \mathrm{m}^{3}$ as the kerogen content decreases. At the higher densities (low kerogen content) the material tends to develop appreciable porosity, perhaps as much as 118 by volume. Porosity, even in small amounts on the order of 18 , produces changes in the Hugoniot response, especially at low stress levels.

The strong visual indication of bedding suggests that the material may be mechanically anisotropic. In fact, quasi-static compressive uniaxial and triaxial tests confirm that the material is transversely isotropic. However, the very high pressure Hugoniot results of Carter ${ }^{2}$ indicated no anisotropy effects within the limit of experimental error. Hugoniot results at low stress levels, where strength variations are more readily observed, have tended to be confusing. In view of the rather limited data from any one investigation and marked density variations possible with this material, this is not surprising. 


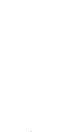


The available low stress Hugoniot data on nonporous (moderate to high kerogen content) oil shale consist of:

(1) Halleck's $\mathrm{s}^{3}$ experiments based on plate impacts using air gun driven specimens onto quartz transducers to give direct impact Hugoniot data; measured quantities are projectile velocities and impact stress level, with the quartz elastic response known.

(2) Olinger's $s^{4}$ experiments based on air gun driven plate impactors of oil shale impacting sandwich targets of oil shale instrumented between the individual shale layers with foil Manganin piezoresistive gauges; measured quantities were the stress-time histories of the transmitted wave at the gauge location and the time of impact; these records were analyzed initially to give Hugoniot results by olinger and subsequently by Murri et al., 5 .

(3) Schuler et al. 6 performed direct impact Hugoniot experiments of air gun driven quartz gauge impactors onto oil shale targets; measured quantities were impact stress level and impact velocity, with the quartz gauge elastic response known; Munson ${ }^{1}$ analyzed the direct impact results to yield Hugoniot data.

(4) $\mathrm{Grady}^{7}$ has unpublished results of Michelson interferometry measured particle velocity-time histories of a transmitted stress pulse induced in oil shale targets by air gun driven polymethymethacylate impactors; the other measured quantity was the impact time; these results were analyzed by the author to give Hugoniot data.

In these studies, the direction of wave propagation was varied with respect to the normal to the bedding planes from $0^{\circ}$ to $90^{\circ}$. However, there was no apparent attempt to select a narrow range of 
sample densities. For example, Halleck's specimens had density variations of 23\%, unevenly distributed in the two specimen orientations of $0^{\circ}$ and $90^{\circ}$.

In reanalyzing the data, we assumed that density is a major variable and grouped the results according to relatively narrow density bands. These groups are tabulated in Table I as 2.35 $( \pm 2.58), 2.16( \pm 2.38)$ and $1.96( \pm 6.68) \mathrm{Mg} / \mathrm{m}^{3}$. The range of densities within a group is greater than we would prefer, but narrower ranges were not possible with the limited data. The Hugoniot data are given in terms of initial density, $p$, particle velocity, $u$, and shock velocity, $U$. For the data of olinger, 4 several columns of $\mathrm{U}$ values are shown. His tests used embedded gauges sandwiched between layers of oil shale. Numbered columns correspond to these layers, and the calculated shock velocity in each layer was based on transit times through the layer, i.e. between gauges. The first layer does not have a shock velocity value because of uncertainty in the impact time in the experiments. The reanalysis columns pertain to the reanalysis made by Murri et al. 5 to adjust for gauge response differences. Reanalysis values are essentially the same as the original values.

All these data could be plotted; however, in the interest of clarity, we plot only the 2.35 and $1.96 \mathrm{Mg} / \mathrm{m}^{3}$ density groups in Fig. 1. Also shown are the high pressure Hugoniot data of Carter ${ }^{2}$ for approximately the same density groups. The Carter data, in this instance, are for oil shales without apparent porosity. High pressure Hugoniot results above particle velocities of $1.6 \mathrm{~km} / \mathrm{s}$ have not been included because of the suspected dolomite phase change. ${ }^{l}$ Results of schuler et al. ${ }^{6}$ are not plotted because their results are affected by the porosity of the material they studied. 


\section{DISCUSSION OF DATA}

\section{Particle Velocity}

Although experimental scatter exists due to both the normal experimental errors and the variation of density, within a group we see that a consistent data trend exists. The 01 inger ${ }^{4}$ data and Carter ${ }^{2}$ data are in fact quite consistent, with somewhat more experimental scatter in the Halleck ${ }^{3}$ results. Again, these results are plotted regardless of orientation. Crude best fit curves (dashed lines) drawn through the data are shown in Fig. 1.

At low particle velocities, the apparent Hugoniot: "shock" velocity decreases with particle velocity to a minimum value. This suggests considerable structure in the compressive wave at low stresses. While this response is similar to elastic-plastic behavior, detailed wave profile observations show no evidence of distinct elastic and plastic waves developing over propagation. distances of $25 \mathrm{~mm}$ or more. Thus, the response is undoubtedly associated with a continuous wave profile which continues to spread with increasing particle velocity. Based on direct impact calculations or half-amplitude velocities of transmitted waves, the Hugoniot results for such a spreading compressive wave would produce similar effects. We postulate that the rock material is behaving in an "elastic" manner but with progressive "yielding" similar to that observed in porous materials. Obviously, the presence of kerogen in the pores modifies the collapse process considerably, giving rise to the structure in the compressive wave front.

It appears that the magnitude of the dip in the shock velocities. with particle velocity is less pronounced for the low density data: A trend of this type is consistent with a decrease in initial elastic modulus as the amount of rock material is decreased. 
Mixture model calculations based on hydrodynamic response given by Munson ${ }^{1}$ for 2.35 and $1.90 \mathrm{Mg} / \mathrm{m}^{3}$ materials are reproduced here (solid lines of Fig. 1). They represent the high pressure data well but are in obvious error, as would be expected, at low pressures or particle velocities.

\section{Orientation Dependence}

At this point, we wish to address the orientation dependence of the shock velocity. Since the orientation dependence is related to material strength, it must be examined at low stress levels, where the magnitude of the deviatoric stress relative to the spherical stress is greatest. Also, we must attempt to obtain data at a constant particle velocity and density, since both of these variables are important. In searching the data, we find that meeting all these requirements is very difficult, and consequently, it will be necessary to make corrections for the change in shock wave speed with particle velocity. For now, no corrections will be made for the density variation within the specific density groups. Even with particle velocity corrections, a sufficient data base for studying orientation dependence is available only within the $2.35 \mathrm{Mg} / \mathrm{m}^{3}$ density group. Using data over the range in u from 0.045 to 0.113 $\mathrm{km} / \mathrm{s}$ and applying a small correction to adjust the data to a $\mathrm{u}$ of $0.05 \mathrm{~km} / \mathrm{s}$, results in the upper data collection of the inset in Fig. 1 (the raw data are plotted with an arrow indicating the amount of correction). The angle is that between the normal to the bedding planes and the direction of wave propagation. Also shown on the inset graph is a dashed line connecting average shock velocities at $0^{\circ}$ and $90^{\circ}$. Even though the scatter is large, we have drawn a curved solid line which accommodates the data at $60^{\circ}$. No data exists for $u$ between 0.045 and $0.113 \mathrm{~km} / \mathrm{s}$ for the $1.96 \mathrm{Mg} / \mathrm{m}^{3}$ material, except at $0^{\circ}$ so we cannot extend the analysis here. 
In a sense we can add to the data base from results of Schuler et al. 6 on 98 porous low kerogen oil shale. While the porosity introduces another factor, the sedimentary nature of the shale remains. Structurally, the shale determines the strength properties. These data at about $\mathrm{u}=0.17 \mathrm{~km} / \mathrm{s}$ and $\rho=2.35 \mathrm{Mg} / \mathrm{m}^{3}$ are also given in Table I and plotted in the inset of Fig. I. Again, a great deal of experimental scatter is observed because of density and particle velocity variation, as well as from the normal experimental error; however, the trends are essentially the same as the other data.

The curves suggest a weak minimum between $0^{\circ}$ and $45^{\circ}$. If the results are representative, anisotropy in wave propagation velocities at this stress level is less than 158 . 


\section{CONCLUSIONS}

Analysis of available low stress Hugoniot data on Anvil Points oil shale has revealed several significant trends, or at least indications of trends. It is clear from the analysis that available data were generated with rather wide variation in critical experimental parameters, notably density, and as a consequence, data selection to isolate a given variable is difficult. Regardless of this difficulty, the analysis suggests the low stress data are a strong function of the specimen kerogen content, as related to the density, and are compatible with the earlier high stress Hugoniot data. Measured shock velocity, for a given kerogen content material, shows a minimum in the shock velocity-particle velocity plane. Such behavior is related to a markedly structured compressive wave front which is ignored by a Hugoniot analysis. Further, this behavior is thought to result from yielding at low stresses in a manner analogous to porous materials.

At low stress levels, where experimental resolution is adequate to observe such effects, the oil shale shows a slight variation $(\sim 158$ in shock wave speed as the wave propagation direction changes with respect to the bedding planes. Sufficient data on solid material were available to demonstrate the orientation dependence of wave velocity for only one kerogen content at one given particle velocity. However, another data set, for 98 porous oil shale, showed essentially similar response. This was the first clear indication of wave propagation anisotropy magnitudes which is not based on ultrasonic studies. 


\section{REFERENCES}

1. D. E. Munson, "Analysis of High Pressure Oil Shale Hugoniots," SAND 77-0118, Sandia Laboratories, Albuquerque, New Mexico (February 1977).

2. W. J. Carter, "Hugoniot of Green River Oil Shale," Explosively Produced Fracture of Oil Shale: Progress Report I. Third Quarter FY 76, Los Alamos Scientific Laboratory, Los Alamos, New Mexico (May 1976).

3. P. M. Halleck, "The Hugoniot Response of Oil Shale at 1.0-3.7 GPa Pressure," Explosively Produced Fracture of Oil Shale, July-September 1976, LA-6594-PR, Los Alamos Scientific Laboratory, Los Alamos, New Mexico (December 1976).

4. B. Olinger, "Oil Shale under Dynamic stress, Part II," Explosively Produced Fracture of Oil Shale, July 1-June 30, 1976, LA-6521-PR, Los Alamos Scientific Laboratory, Los Alamos, New Mexico (September 1976).

5. W. J. Murri, D. A. Schockey and C. Young, "Dynamic Fracture and Fragmentation of oil Shale," (Report) Stanford Research Institute, Menlo Park, California (February 1977).

6. K. W. Schuler, P. C. Lysne and A. L. Stevens, "Dynamic Mechanical Properties of Two Grades of Oil Shale," Int. J. Rock Mech. Min. Sci., 13, 91 (1976).

7. D. E. Grady, Sandia Laboratories, Albuquerque, New Mexico (private communication). 


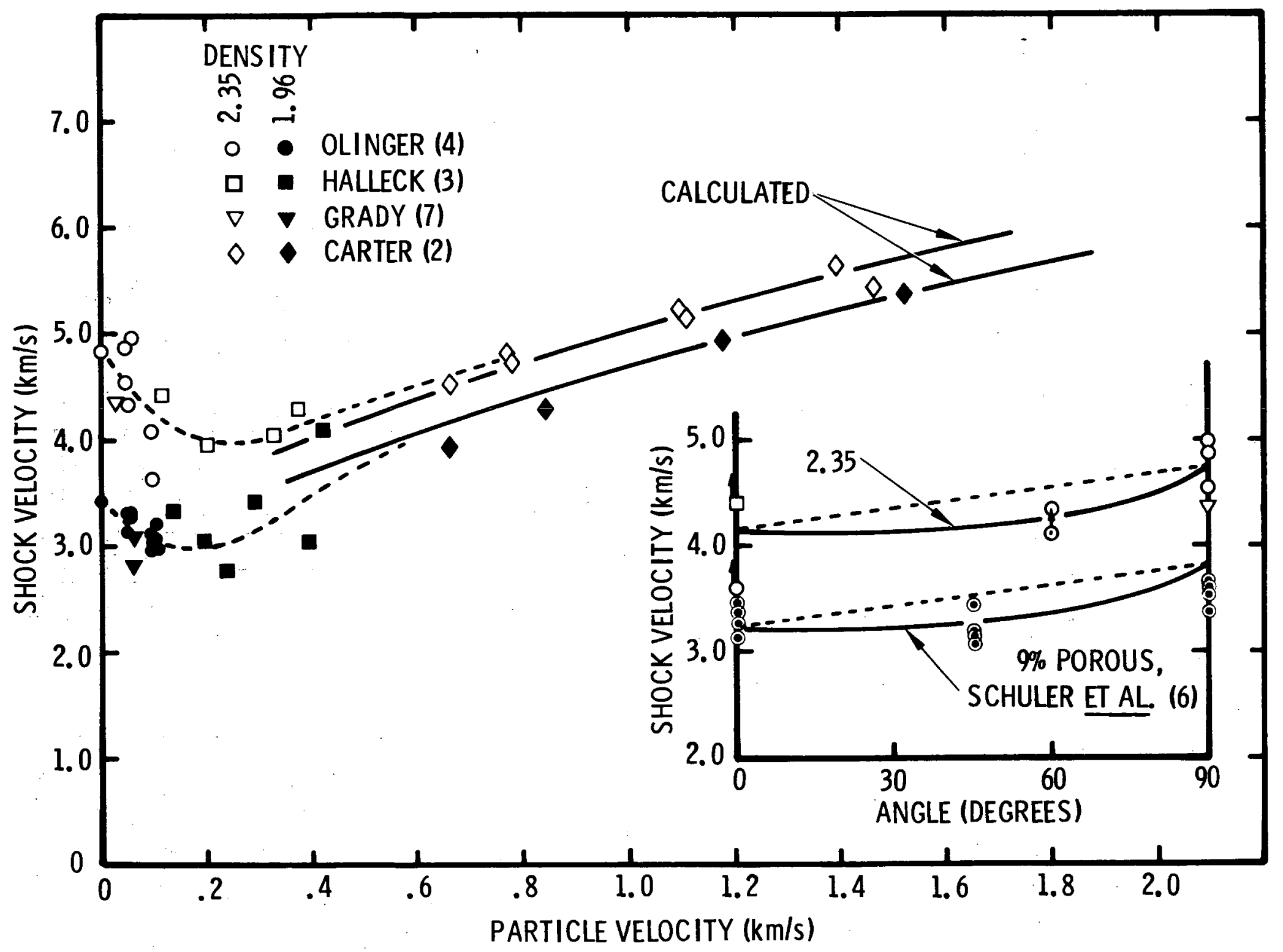

Fig. 1. Hugoniot Data for Oil Shale 
Table I. Low Stress Level Hugoniot Data

Non-Porous Material

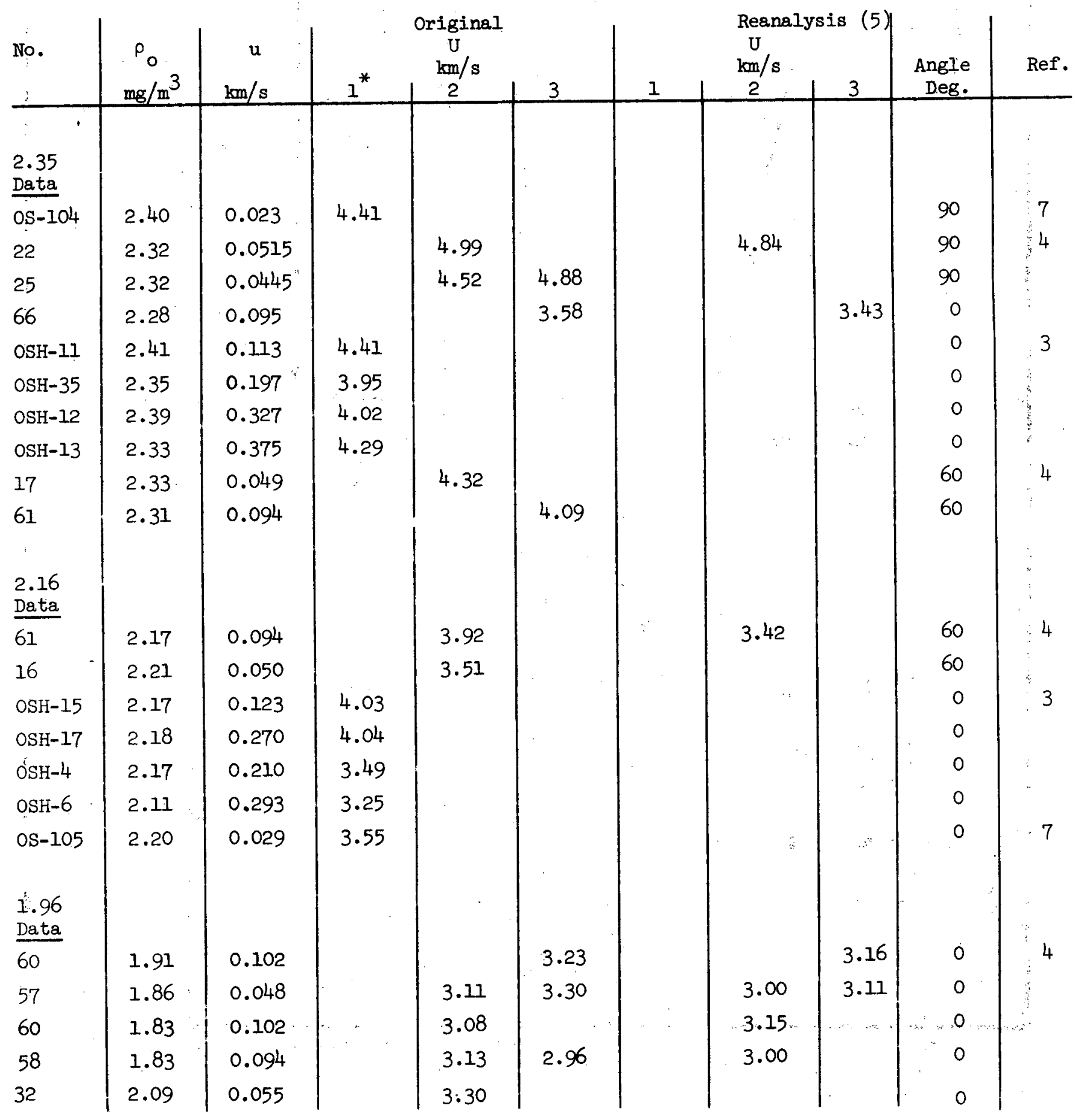


Table I (cont'd)

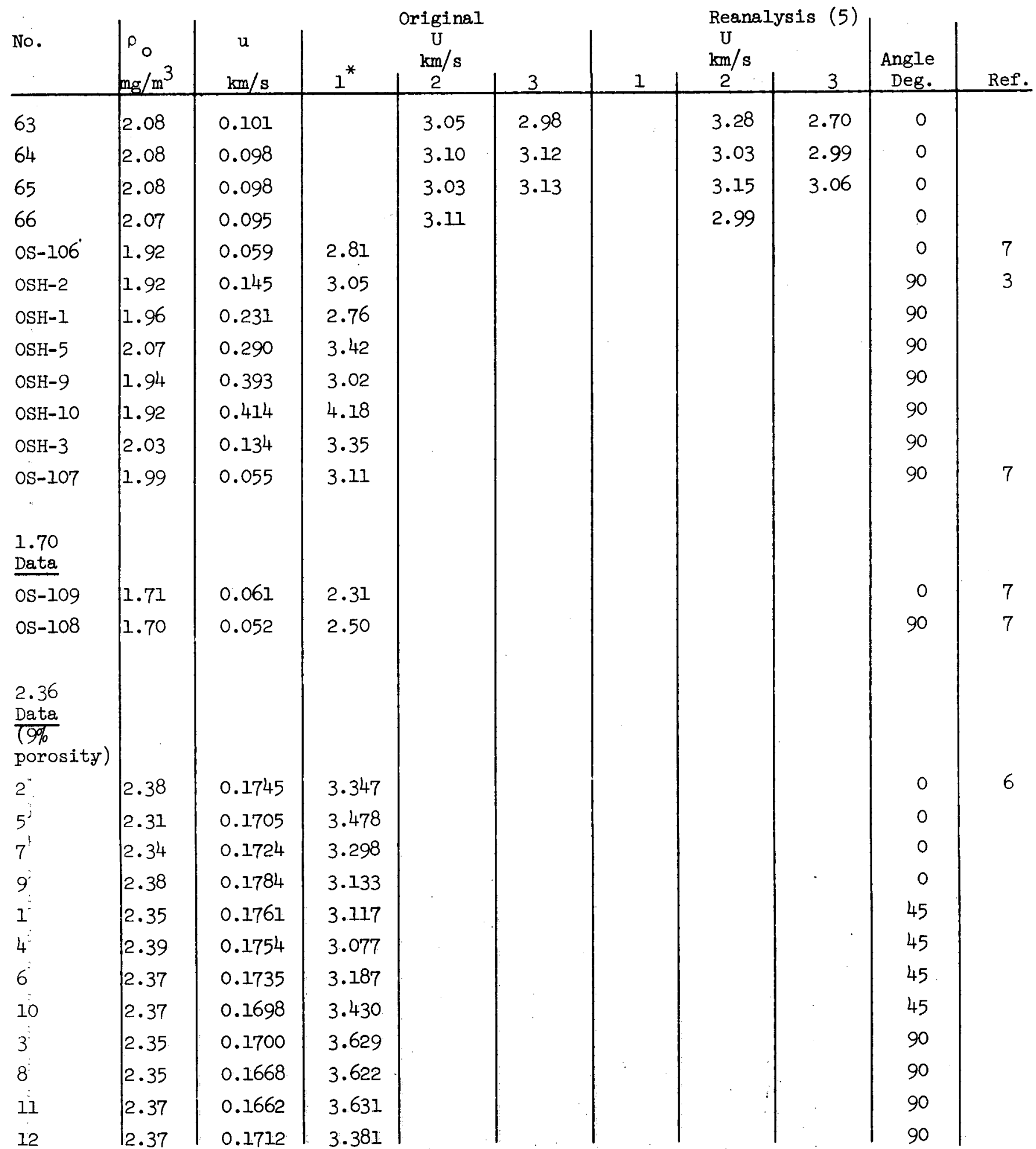

* The Olinger data were obtained from sandwich samples assemblies where individual layers had different densities. Shock velocities were caluclated from layer transit times; the identities are preserved here. 


\section{Distribution:}

Mr. Hugh Guthrie, Director

Oil, Gas and Shale Technology

U. S. ERDA Fossil Energy

20 Massachusetts Avenue NW

Washington, DC 20545

Dr. Phillip C. White

Assistant Administrator

U. S. ERDA Fossil Energy

20 Massachusetts Avenue NW

Washington, DC 20545

Mr. Jerry Ramsey

Mr. H. E. Thomas

U. S. ERDA Fossil Energy

Branch of Oil Shale

Conversion

Room 4121

20 Massachusetts Avenue NW

Washington, DC 20545

Mr. L. M. Burman

Oil, Gas and Shale Technology

U. S. ERDA Fossil Energy

20 Massachusetts Avenue NW

washington, DC 20545

Harry C. Carpenter

R. Martel

Laramie Energy Research Center

P. O. Box 3395, Univ. Sta.

Laramie, wyoming 82071

W. J. Carter, M- 6

Los Alamos Scientific Laboratory

Los Alamos, New Mexico 87544

A. E. Lewis

Lawrence Livermore Laboratory

University of California

P. O. Box 808

Livermore, CA 94550

5000

5100

5160

5163

5700

5730

5731

5732

5733

5734

5734
A. Narath
J. K. Galt
W. Herrmann
D. E. Munson (25)
J. H. Scott
H. M. Stoller
R. K. Traeger
D. A. Northrop
C. L. Schuster
A. L. Stevens
R. R. Boade

3141

C. A. Pepmueller (5)

W. L. Garner (3)

for ERDA/TIC (25)

Attn: R. P. Campbell 3172-3 